\title{
Challenging the safety and efficiency of homeopathy: Ignatia amara as an example, ants as models
}

\begin{abstract}
Homeopathic treatments are considered by the vast majority of the scientific community as non-effective, apart from a well-documented placebo effect. Nevertheless, some experimental results raise questions about their efficiency, and numerous practitioners still consider homeopathy as an efficient alternative treatment instead of usual pharmaceutical drugs. Homeopathy is thus nowadays debated among the general public, practitioners and medical schools, and is still used by many patients in search for "natural" treatments. It is therefore relevant to bring information to feed this debate and to investigate the efficiency and safety of homeopathic drugs. We examined on ants, used as biological models, the effects of a homeopathic drug, Ignatia amara, advocated to ease symptoms of stress. We tested the effects of this drug on ant's ethological and physiological traits (1) under normal condition, then (2) under a stressing situation. We found that (1) this drug was not without adverse effects but slightly impacted some ants' traits; (2) this drug could reduce the adverse effects caused by the stressing situation. It nearly fully restored the ants' locomotion, orientation ability, audacity, tactile perception, brood caring, social relationship, escaping behavior, cognition, and slightly the memory. No adaptation and no habituation to the effects of Ignatia amara occurred, and no dependence on its consumption developed. The causes and mechanisms of these effects remain unknown to us, but our results support the hypothesis that, in some given cases, for some specific health problems, and using adequate product(s) and dose(s), a homeopathic treatment based on Ignata amara extracts could help patients to recover from stress symptoms.
\end{abstract}

Keywords: cognition, locomotion, Myrmica sabuleti, social relationships, stress
Volume 4 Issue | - 2019

\author{
Marie-Claire Cammaerts,' David \\ Cammaerts $^{2}$ \\ 'Independent researcher, retired from the Biology of Organisms \\ Department, University of Brussels, Belgium \\ 2Independent researcher, Belgium
}

Correspondence: Marie-Claire Cammaerts, 27, square du Castel Fleuri, I I70, Bruxelles, Belgium, Tel 32267349 69,

Email mccammaerts@gmail.com

Received: December 20, 2018 | Published: January 03, 2019

\section{Introduction}

Homeopathy has been founded at the end of the $18^{\text {th }}$ century by the practitioner Hohnemann. It consists in treating patients with the substances causing their health problems, these substances being diluted numerous times in a water (most often) solution. The first dilution $(=1 \mathrm{CH}$, standing for "centésimale hahnemannienne) is the dilution of the substance into 100 times its volume of water (i.e. $1 \mathrm{ml}$ of the substance in $99 \mathrm{ml}$ of water for example). Two $\mathrm{CH}$ is a solution obtained after two successive dilutions, i.e. $1 \mathrm{ml}$ of a $1 \mathrm{CH}$ solution diluted in $100 \mathrm{ml}$ of water. Three, four, five, six etc... CH are solutions obtained after 3, 4, 5, 6 etc... successive dilutions (made each time by mixing one volume of the previous solution with 99 volumes of water). Of course, after many dilutions $(12 \mathrm{CH} \ldots 30 \mathrm{CH})$, there is nearly no molecule of the active substance in the solution, at least from a statistical perspective (at $12 \mathrm{CH}$, the probability of the solution to contain at least one molecule of the active substance is lower than $1 / 10.000)$. For dilution superior to the $15 \mathrm{CH}$, one can consider that there is virtually none molecule of the active substance in the product used for treating patients. Therefore, such a product should have no effect, nor beneficial, nor harmful.

Most of the scientific studies and meta-analysis on homeopathy conclude that such a medicinal treatment is not at all efficient and may even be dangerous ${ }^{1-4}$ Several reports, reviews and internet sites also relate this inefficiency and potential dangerousness. ${ }^{5-11}$ Sometimes, some doubt is however emitted as for a total inefficiency. ${ }^{12,13}$ For instance, a detailed analysis of an homeopathic treatment used for treating children suffering from strong headache, with their success and their failure in leading to health amelioration, has been made by four researchers..$^{14}$ Most of the treated children less suffered from migraine and the authors conclude that one can wonder if the homeopathic alternative medicine may not have, in some cases, some slight beneficial effects. Another scientific work, made in 2014, also showed that homeopathy is not always inefficient. ${ }^{15}$ Nevertheless, one of the major potential cause of the sometimes observed beneficial effect of some homeopathic treatments is the placebo effect, a well-know and well documented effect of numerous medical treatments. ${ }^{16,17}$ In quest of proof for the efficiency or inefficiency of homeopathy, researchers are very often confronted to the confounding placebo effect. Initially thinking that homeopathy is an inefficient complementary medicine and confronted to the different opinions about it related here above, we could not but think that a novel study should be made, without the potential confounding factor of the placebo effect, so to say to conduct an experimental work not on humans, but on naïve biological models, unable to be affected by the placebo effect, and for which some given physiological and ethological traits could be precisely assessed.

We are now accustomed to use ants as biological model organisms for examining the effects of drugs, products and situations used/ experienced by humans. ${ }^{18-22}$ Very often, we observed similar effects than those observed in humans, and revealed some other not yet detected ones. Therefore, we aimed to use again ants as model organisms for examining the safety and the potential efficiency of homeopathic products.

Which homeopathic product could we consider? The product must have potential effects on ants' physiological and/or ethological traits and these effects must be easy to observe and quantify. The eight most 
used homeopathic drugs, derivate from different plant species, are Arnica montano, Oscilla coccinum, Nux vomca, Cocculine, Ignatia amara, Gelsemium, Rhinallergy, Rhus toxicodendrom. ${ }^{23}$ Among them, one of the most appropriate for a study on ants could be Ignatia amara, since this drug is devoted to treat health problems as anxiousness, stress, nervousness. As it is possible to put ants under a stressing situation and to assess their behavior (locomotion, cognition, memory etc...) under such a situation, potential beneficial or adverse effect of this homeopathic treatment should be easily detectable on these insects.

What is nowadays known on Ignatia amara? This homeopathic drug is extracted from the seeds of a plant, Strychnos ignatii (Loganiaceae family), which contains two alkaloids, strychnine and brucine. Theoretically, used at homeopathic doses, such an extract should be efficient for treating hypersensitive, emotional and introvert persons, as well as persons becoming anxious, or stressed, or having health syndromes following problems or difficulties in their social life. Several internet sites describe the health problems Ignatia amara can - theoretically - solve, the effects the drug may have, and the doses to be used. ${ }^{24-28}$ Briefly, Ignatia amara should advantageously be used in case of nervousness, anxiousness, stress, spasms, tract, sleeping problems, and depression. The drug must be used at doses $3,4,5,7$ or $9 \mathrm{CH}$, taken three times per day. In every informative document relative to Ignatia amara (meanwhile all of them being not scientific studies), it is stated that this product has no adverse effects, induces the decrease of the initial health problems, and leads to some health amelioration in general. Is this treatment really effective, or does it have only some placebo effect? In 2012, two authors made a behavioral study on mice and obtained positive results. ${ }^{29}$ One could therefore think that this treatment could be effective and safe. However, this drug contains strychnine (a very toxic substance) and brucine (a less toxic one). ${ }^{30,31}$ Even if these toxic substances are present in very low amounts in the drug, one can worry about the potential harmful effects of this treatment. Therefore, examining the safety and the potential efficiency of the homeopathic drug 'Ignatia amara' on a model organism which is insensitive to the placebo effect (i.e. ants) appeared to be relevant. Here below, we explain why we used ants, which species we used and what we know on it, which traits we intended to look to, and how we proceeded to set up a rigorous experimental protocol for our study.

\section{Why using ants as models?}

Most complex animals' physiological and ethological traits are fundamentally similar. ${ }^{32}$ Generally, they are firstly examined on animals as models (e.g. fruit flies, cockroaches, bees, mice, monkeys), and then studied on humans. ${ }^{33}$ Insects are often used as models because they rapidly develop and can easily be maintained in laboratory. ${ }^{34}$ Hymenoptera, among others, are often used. ${ }^{35}$ Ants could be used. ${ }^{36}$ Indeed, they present complex behavior, among others, colonial regulation, labor division, exchange of information using tactile and chemical signals (pheromones). ${ }^{37-39}$ They construct sophisticated nests, take care of their brood, and chemically mark the different parts of their environment. ${ }^{37}$ They navigate, recruit congeners, relocate their nest, clean its inside and create cemeteries. ${ }^{38}$ Due to such a complex biology and behavior, it can be tried to use them as biological models for studying, among others, the impact of drugs, products, environmental changes on the health, and to emit hypothesis about the effects of these elements on other organisms including humans.

\section{Which species was used and what is known on it?}

As already said above, we have largely studied the ants of the genus Myrmica. We now know rather well their ecology, eyes morphology, angle of vision, visual perception, recruitment strategy, navigation system, learning, as well as the ontogenesis of some of their abilities. ${ }^{40,41}$ Studying the effect of electromagnetic fields (EMF) on their learning, memory and responses to pheromones showed that they can be used as biological models. ${ }^{42,43}$ Indeed, they were so in the course of our studies on them of the harmful impacts of several products used by humans e.g. ${ }^{18-22}$ Here, we used again the ant $M$. sabuleti Meinert 1861 as models for examining the safety and the efficiency of a homeopathic drug chosen as an example for evaluating the validity of homeopathic treatments.

\section{Which traits were considered?}

Fourteen traits were considered: the speed of locomotion, sinuosity of movement, orientation ability, audacity, tactile (pain) perception, brood caring, aggressiveness towards nestmates, and aggressiveness against aliens, escaping ability, cognition, memory, adaptation to potential adverse effects of the drug, habituation to its potential beneficial effects, potential dependence on its consumption. The experimental protocols allowing assessing these traits are well established and have already been used many times with success, what allows only briefly relating our methods as well as comparing here observed effects with some ones previously observed in presence of other drugs or factors e.g. ${ }^{18-22}$

\section{How have we proceeded for conducting our study as correctly as possible?}

The here given explanation are summarized in Table 1. For evaluating the safely of Ignatia amara, we assessed the eleven considered traits on ants living under normal diet, then we gave the homeopathic drug to the ants and assessed again the same eleven traits. We began by the last one, i.e. the memory, in order to do so before the ants lost, as they always do, what they had to learn, then we continued by examining the other ants' traits and we finished by the ants' adaptation to effects of the drug. After these two series of experiments, the ants were again maintained under normal diet, and stayed so during two days without being experimented. After that, pieces of onion (Allium cepa) were set on the ants' foraging area. Onion cells contain 1-propenyl-L-cystein-sulfoxide in their cytoplasm and the enzyme allinase in their vacuome. When cut, several substances are generated, among others 1-propenylsulphenic acid. The latter substance partly becomes by itself thiosulfinate, and is partly transformed into propanethial-S-oxyde due to the action of the lachrymal factor synthase. All these substances interact with chemical receptors on ants' antenna and induce various behavioral and physiological effects, all together called as "stressing effects" or "stressing factor" hereafter. ${ }^{44}$ The eleven considered traits were then again assessed on these ants submitted to the stressing factor. This having been done, the ants (still with onion on their foraging area) received Ignatia amara in their sugar water, and the eleven traits were once more assessed. We again began by the last one, i.e. the memory, for the same reason as here above, then we continued by examining the other ants' traits, and finished with the ants' habituation to effects of the drug. After the end of the fourth series of experiments, the pieces of onion were removed from the ants' tray, and these insects received again pure sugar water. 
Table I Experimental planning

$\begin{array}{ll}\begin{array}{l}\text { I. control I, normal } \\ \text { diet }\end{array} & \begin{array}{l}\text { assessment of ants' eleven traits, the last one being } \\ \text { the memory (using a green cube); giving lgnatia } \\ \text { amara to the ants }\end{array} \\ & \begin{array}{l}\text { assessment of the ants' eleven traits, the first } \\ \text { assessed (but the last related) being the memory of } \\ \text { the green cube; assessment of the ants' adaptation;' } \\ \text { II. diet with lgnatia } \\ \text { amara }\end{array} \quad \begin{array}{l}\text { setting ants under normal diet again, and waiting } 2 \\ \text { days before re-experimenting }\end{array}\end{array}$

III. control 2, normal assessment of ants' eleven traits, the last one being diet + onion in the memory (using a yellow cube); giving Ignatia the trays amara to the ants

\section{IV. diet with Ignatia amara + onion in the trays}

assessment of the ants' eleven traits, the first assessed (but the last related) being the memory of the yellow cube;' assessment of the ants' habituation; assessment of ants' potential dependence; setting ants under normal diet again, and removing the pieces of onion from the trays

Physiological and ethological traits were firstly assessed on ants living under normal diet and normal condition (I), then on ants living under a diet with Ignatia amara and under normal condition (II) in order to evaluate the safety of that homeopathic drug. After that, the same assessments were conducted on ants living under normal diet and in presence of onion odor (III) which induced nervousness, stress and affected some ants' traits. Finally, the same assessments were performed on ants living in presence of onion odor and under a diet with Ignatia amara (IV) in order to evaluate the efficiency of that homeopathic drug in reducing the nervousness, the stress and so the impacts induced by onion odor.

\section{Material and methods}

\section{Collection and maintenance of ants}

The experiments were conducted on two colonies collected in September 2018 in the Aise valley (Ardenne, Belgium) in an abandoned quarry. The ants nested under stones and contained 400 600 workers, brood and a queen. Another colony collected in June 2018 at Marchin (Belgium), in an abandoned quarry, furnished the aliens used during the experiment on the ants' aggressiveness. Each colony was maintained, as usual, in two glass tubes half filled with water, with a cotton plug separating the ants from the water e.g. ${ }^{18-22}$ These nest tubes were deposited in a tray $(34 \mathrm{~cm} \times 23 \mathrm{~cm} \times 4 \mathrm{~cm})$. The ants received pieces of Tenebrio molitor larvae (Linnaeus, 1758) three times per week, and had permanently sugar water in cotton plugged tubes. The ants of the same colony are here often named 'nestmates'. The ambient temperature was $c a 20^{\circ} \mathrm{C}$, the humidity $80 \%$, the lighting 330 lux, and the electromagnetism surrounding field $2 \mu \mathrm{Wm}^{2}$, all this being optimum for the species.

\section{Giving Ignatia amara to the ants}

A package of Ignatia amara 5 CH, Boiron ${ }^{\circledR}$ (F 69510 Messigny) was provided by the drugstore Wera (1170 Bruxelles). Humans are advised to consume one tablet of this $5 \mathrm{CH}$ dose three times per day. Humans treated with Ignatia amara consume thus 3 tablets of this product together with about $1.000 \mathrm{ml}$ of water i.e. the usual humans' intake of water. Insects, and thus ants, due to their physiology, consume about 10less water than mammals. Consequently, for providing the ants with an Ignatia amara diet similar to that of humans, they must be provided with a solution of 3 tablets in $100 \mathrm{ml}$ of water. Therefore, we made a solution of 1 tablet in $33 \mathrm{ml}$ of sugar water (that usually given to the ants) and delivered this solution to the ants in their usual

sugar water tubes plugged with cotton. We checked three times per day if the ants effectively consumed the provided solution, and they did. Let us recall that the ants were firstly maintained under normal diet (to perform a first series of control experiments), then received a sugar solution of Ignatia amara instead of their usual sugar water and the first series of test experiments were conducted. After what, the ants were again maintained under normal diet and pieces of onion were set on their foraging area. Two days later, a second series of control experiments was performed. Thereafter, the ants received again sugar solution of Ignatia amara instead of their usual sugar water, and the second series of experiments were conducted (Table 1). First control experiments and series of experiments allowed examining the safety of Ignatia amara; second control experiments and series of experiments allowed examining its efficiency

\section{Setting onion on the ants' tray}

We simply deposited 16 pieces (about $1 \mathrm{~cm}^{3}$ ) of onion on the two colonies' foraging area, between the nest entrances and the food sites, and refreshed these pieces each two days. Let us recall that the pieces of onion produced chemical compounds which act as a "stressing factor" and cause various physiological and ethological effects in ants, an event we analyzed in a previous work. ${ }^{44}$

\section{Linear and angular speeds, orientation}

These traits were quantified on ants moving on their foraging area, their speeds without stimulating them, their orientation while stimulating them with a nestmate tied to a piece of paper (Figure 1(A1, A2)) \& (Figure 2 (A1, A2)).e.g. ${ }^{18-22}$ Such a nestmate emits its alarm attractive mandibular glands pheromone. For the ants' speeds and for their orientation, the trajectory of 40 workers was recorded and analyzed using appropriate software. ${ }^{45}$ The linear speed (in $\mathrm{mm} / \mathrm{s}$ ) is the length of a trajectory divided by the time spent to travel it; the angular speed (in angular degree/cm=ang.deg. $/ \mathrm{cm}$ ) is the sum of the angles made by successive adjacent segments, divided by the length of the trajectory; the orientation (in ang. deg.) towards a location is the sum of the successive angles made by the direction to the location and the direction of the trajectory, divided by the number of angles measured. When the final angle value is lower than $90^{\circ}$, the animal tends to orient itself towards the location; when the value is larger than $90^{\circ}$, it tends to avoid the location. The median and quartiles of each distribution of 40 values were established.

\section{Audacity}

As previously, a cylindrical tower (height $=4 \mathrm{~cm}$; diameter $=1.5 \mathrm{~cm}$ ) tied to a squared platform $\left(9 \mathrm{~cm}^{2}\right)$, made of white Steinbach ${ }^{\circledR}$ paper, was deposited in the ants' foraging area, and those present at any place on this apparatus were counted 10 times over 10min (Figure 1(B1, B2)) \& ((Figure 2(B1, B2)).e.g. ${ }^{18-22}$ The counts obtained for the two colonies were added, and the mean and the extremes of these added counts were established. Then, the counts obtained for two successive minutes were added for statistical analysis.

\section{Tactile (pain) perception}

Ants perceiving the uncomfortable character of a rough substrate walk on it slowly, sinuously, and with difficulties. Ants weakly perceiving such an uncomfortable character walk more quickly and less sinuously. Therefore, for assessing the ants' tactile perception, the ants' locomotion on a rough substrate was analyzed (as usually, see above 'Linear and angular speeds'). As previously, a folded piece $(3 \mathrm{~cm} \times 2+7+2=11 \mathrm{~cm})$ of emery paper $\mathrm{n}^{\circ} 280$ paper was tied to the bottom and the borders of a tray $(15 \mathrm{~cm} \times 7 \mathrm{~cm} \times 4.5 \mathrm{~cm})$, and the tray 
had then a first zone $3 \mathrm{~cm}$ long, a second zone $3 \mathrm{~cm}$ long containing the emery paper, and a last zone $9 \mathrm{~cm}$ longe.g. ${ }^{18-22}$ Such an apparatus was constructed for each colony. For making an experiment, 12 ants of each colony were deposited in the first zone of their apparatus, and the trajectory of 24 ants walking on the emery paper was recorded (Figure 1(C1, C2), Figure 2(C1, C2)). The ants' linear and angular speeds were then assessed as usually, and the median and quartiles of the obtained distributions of values were established.
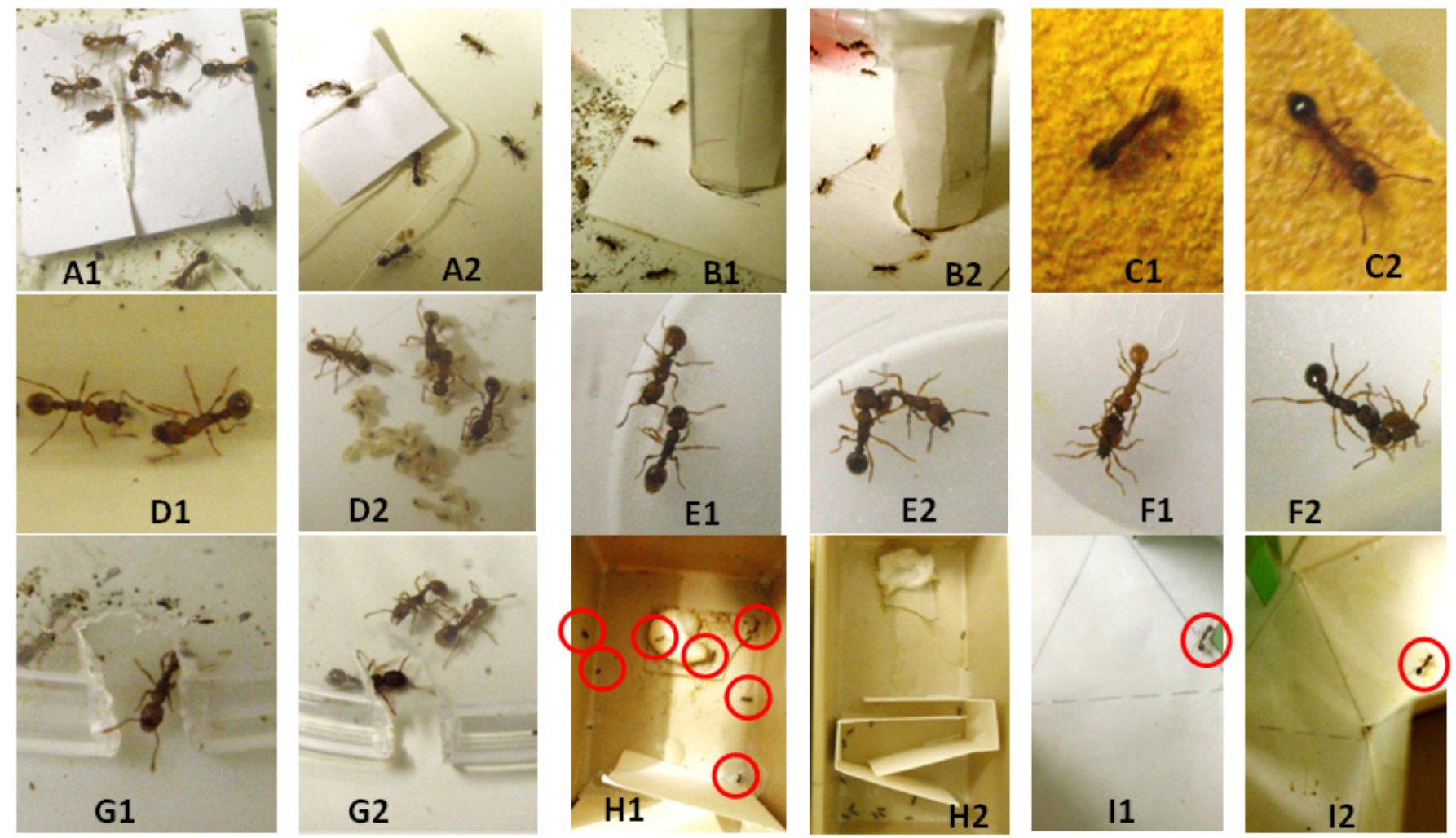

Figure I Some views of the experiments on ants under normal diet (I) and ants under a diet with lgnatia amara (2). (A) Ants coming to a tied nestmate and doing so less well under Ignatia amara diet. (B) Ants coming onto an unknown apparatus and doing so largely under lgnatia amara diet. (C) Ants moving with difficulty on a rough substrate but less perceiving the uncomfortable character of the substrate when under lgnatia amara diet. D:Two ants under normal taking care of a larva; three ants under Ignatia amara diet taking care of one larva, and one doing nothing. (E) Two nestmates, one of those under lgnatia amara diet being a little aggressive. F:Ants stinging an alien. (G) An ant under normal diet escaping and ants under lgnatia amara diet not escaping from an enclosure. (H) Seven ants under normal diet and no ant under Ignatia amara diet having reached the large area beyond a difficult path. (I) an ant trained to a green cube giving the correct response when under normal diet, and the wrong response when being under lgnatia amara diet.

\section{Brood caring behavior}

For each colony, a few larvae were removed from the nest and deposited in front of the entrance. Five of these larvae, and the ants' behavior towards them, were observed (Figure 1(D1, D2), Figure 2(D1D2)). The larvae among these $5+5=10$ not yet re-entered in the nest were counted after 5 seconds, $2,4,6,8$, and 10minutes.

\section{Aggressiveness against nestmates and against aliens}

As previously, these traits were assessed, for each colony, during five dyadic encounters between an ant of the colony and either a nestmate or an alien ant.e.g. ${ }^{18-22}$ Each encounter took place in a cylindrical cup (diameter $=2.5 \mathrm{~cm}$, height $=1.8 \mathrm{~cm}$ ) and lasted 5 minutes. The numbers of times the observed ants did nothing (level 0 of aggressiveness), contacted the opponent with its antennae (level 1 ), opened its mandibles (level 2), gripped the other ant (level 3), and tried to sting or stung the opponent (level 4) were counted (Figure 1(E1, E2, F1, F2)), (Figure 2(E1, E2, F1, F2)). The numbers obtained for the two colonies were added. The ants' aggressiveness was also characterized by "a" = number of aggressiveness levels $2+3+4 /$ number of levels $0+1$.

\section{Escaping ability}

For each colony, 6 ants were enclosed under a reversed polyacetate glass $(\mathrm{h}=8 \mathrm{~cm}$, bottom diameter $=7 \mathrm{~cm}$, ceiling diameter $=5 \mathrm{~cm})$ set in the ants' traye.g. ${ }^{18-22}$ A notch had been made in the bottom rim of the glass ( $3 \mathrm{~mm}$ height, $2 \mathrm{~mm}$ broad) for allowing the ants escaping (Figure $1(\mathrm{G} 1, \mathrm{G} 2))$, (Figure 2(G1, G2)). Thirty seconds, 2, 4, 6, 8, 10 and 12 minutes after the ants had been enclosed, those escaped and those still enclosed were counted. The results obtained for the two colonies were added. The ants' ability in escaping was also assessed by the proportion ' $\mathrm{n}$ ' of ants escaped after $12 \mathrm{~min} / 12$ '. Note that the ability in escaping is reduced in case of stress and of decreased cognition.

\section{Cognition}

The experimental protocol set up when studying the effects of nicotine was again employed. ${ }^{46}$ An experimental apparatus was build for each colony. Two pieces of white paper (Steinbach ${ }^{\circledR}, 12 \mathrm{~cm} \mathrm{x}$ $4.5 \mathrm{~cm})$ duly folded were inserted in a tray $(15 \mathrm{~cm} \times 7 \mathrm{~cm} \times 4.5 \mathrm{~cm})$, dividing the tray into a first small zone, a zone with twists and turns, and a large zone into which some wet cotton had been placed (Figure 1(H1, H2)), (Figure 2(H1, H2)). For conducting an experiment, 
15 ants of each colony were transferred into the first zone of their apparatus, and the ants present in this zone and in the large one were
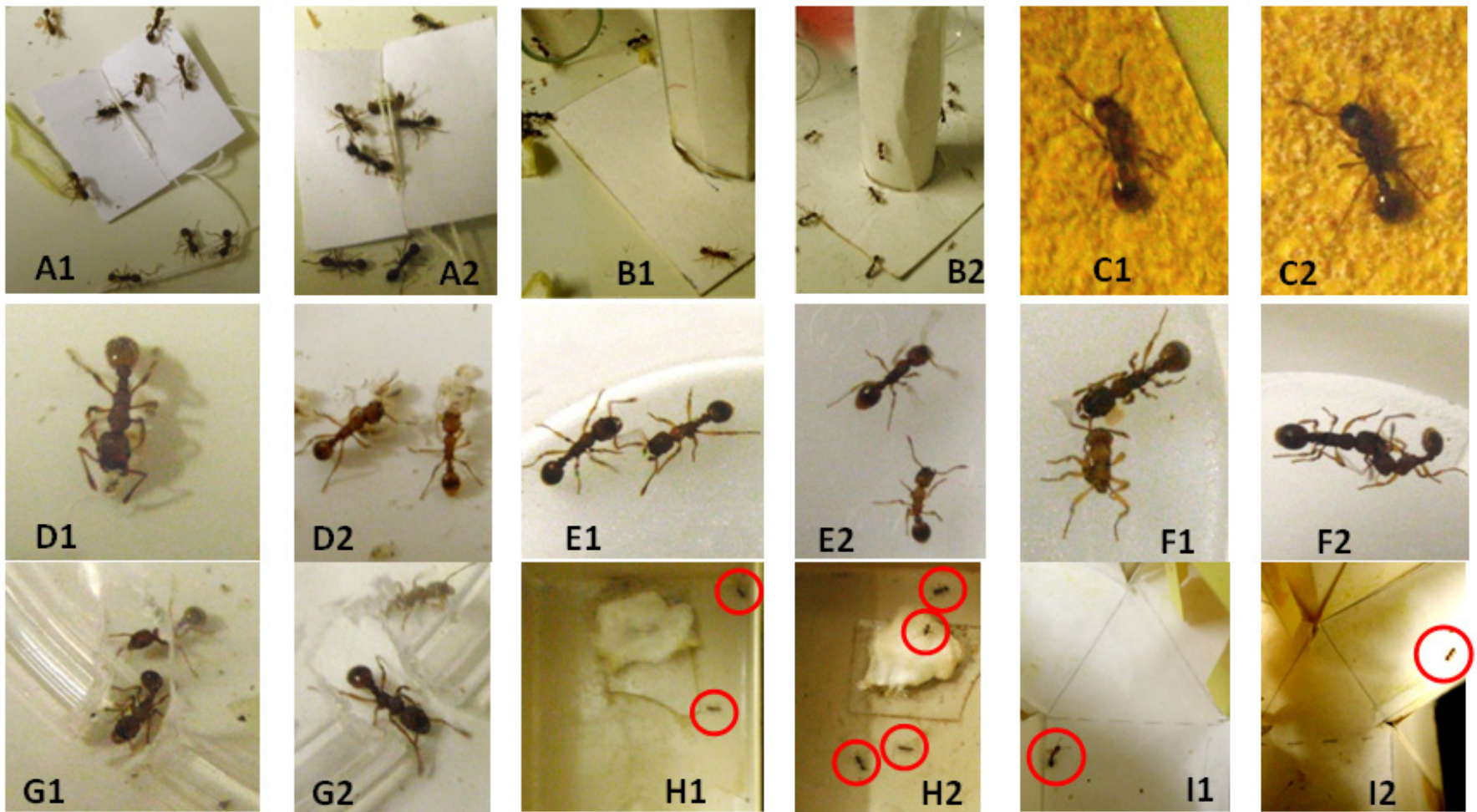

Figure 2 Some views of the experiments on ants living in presence of onion under normal diet (I) and in presence of onion under a diet with Ignatia amara (2). (A) Ants coming to a tied nestmate and doing so better under a diet with lgnatia amara. (B) Ants coming onto an unknown apparatus and being more numerous in doing so under a diet with Ignatia amara. (C) Ants moving on a rough substrate, easily in I, with difficulties in 2 since perceiving the rough character of the substrate and touching the later with the antennae. (D) Ants caring of larvae, doing so promptly in 2. E: two nesmates slightly aggressive in I and not in 2. (F) Ants aggressing an alien.(G) Ants escaping from an enclosure, doing so more frankly in 2. (H) Two ants in I, and 4 ants in 2 having reached the large area beyond a difficult path. (I) Ants trained to a yellow cube tested in a Y-apparatus, hesitating in I and having given the wrong response in 2.

\section{Conditioning and memory}

In a first time, under control conditions, a green hollow cube was set above the entrance of the sugar water tube of the two colonies, and under normal conditions with pieces of onion on the foraging area, a yellow hollow cube was similarly set. The ants went so, each time, through visual conditioning. Their acquisition of such a conditioning was checked by making tests over time until their conditioning score no longer increased. To make a test, 10 ants of colony A and of colony B were individually tested in a Y-apparatus provided with a green (or a yellow) hollow cube in one of its branch. The Y-apparatus was made of strong white paper and was deposited in a tray $(30 \mathrm{~cm} \times 15 \mathrm{~cm}$ $\mathrm{x} 4 \mathrm{~cm}$ ). The green (or yellow) cube was randomly located in the right or the left branch of this Y-apparatus. Moving into the branch containing the cube was considered as giving the correct response (Figure 1(11I2), (Figure 2(I1I2)). Each test provided the response of 20 ants, and from them, the proportion of correct responses. After the ants were duly conditioned, their sugar water was replaced by the aqueous sugared solution of Ignatia amara, and 4 hours later, tests in Y-apparatus were made to assess the ants' conditioning score, and through this score, their short term memory. The short term memory of ants under Ignatia amara diet was thus examined in priority, before assessing the other ants' traits. It must be done in this order because, if the memory would have been examined later, the ants would have forgotten the association between the green (or the hollow) cube (CS) and the sugar water (US).

\section{Adaptation to potential adverse effects of Ignatia amara}

Adaptation occurs when an adverse effect of the drug becomes lower and lower in the course of the drug consumption. In the present work, the ants' linear and angular speeds were again assessed after eight days of Ignatia amara consumption, as they had been assessed after one day of this drug consumption, and the obtained results were compared to the control ones and to those obtained after one day of consumption.

\section{Habituation to potential beneficial effects of Ignatia amara}

Habituation to a drug occurs when a beneficial effect of the drug becomes lower and lower in the course of this drug consumption. Here, the ants' linear and angular speeds were again assessed after they had consumed Ignatia amara during eight days having pieces of onion on their foraging area, exactly as it has been assessed after one day of consumption with pieces of onion on the foraging area. The results obtained with pieces of onion on the foraging area under normal diet, under Ignatia amara diet since one day, and under Ignatia amara diet since eight days were compered.

\section{Dependence on Ignatia amara consumption}

This was examined on ants consuming the homeopathic drug and living in presence of onion odor. Dependence on a substance occurs 
when individuals consuming this substance preferred food containing it to food free of it. As in previous works, for each colony, 15 ants were transferred into a tray $(15 \mathrm{~cm} \times 7 \mathrm{~cm} \times 5 \mathrm{~cm})$ containing two tubes $(\mathrm{h}=2.5 \mathrm{~cm}$, diam. $=0.5 \mathrm{~cm})$, one filled with sugar water, and the another filled with the sugar solution of Ignatia amara used throughout the present work e.g. ${ }^{18-22}$ The tube containing the drug was located on the right in one tray, and on the left in the other tray. The ants coming onto each tube were counted 15 times over $15 \mathrm{~min}$. The counts corresponding to each kind of liquid were separately added, and the counts obtained for the two colonies were added.

\section{Statistical analysis}

The numerical results concerning the ants' linear speed, angular speed, orientation, tactile perception, aggressiveness against nestmates and against aliens, as well as memory were ranked. Those obtained on ants under Ignatia amara diet were statistically compared to those obtained on ants under normal diet. Those obtained on ants under Ignatia amara diet in presence of onion were statistically compared to those obtained on ants under normal diet in presence of onion. These comparisons were made using the non-parametric $\chi^{2}$ test. ${ }^{47}$ As for the ants' audacity, brood caring, escaping behavior and cognition, the similar comparisons were made using the non-parametric test of Wilcoxon. ${ }^{47}$ Ants' dependence on Ignatia amara consumption was statistically analyzed using the non-parametric goodness of fit $\chi^{2}$ test. $^{47}$

\section{Results}

\section{Safety of Ignatia amara (parts I and II (Table I) of the work)}

Linear and angular speeds: The ants' linear speed was slightly not significantly decreased by Ignatia amara consumption (Table 2, line $1 ; \chi^{2}=0.56, \mathrm{df}=2,0.70<\mathrm{P}<0.80$ ). Their angular speed was somewhat poorly significantly increased by that drug consumption (Table 2 , line 2; $\chi^{2}=5.88, \mathrm{df}=2,0.05 \sim \mathrm{P}<0.10$ ), an impact obvious to observers. Eight days later, it was examined if ants adapted themselves to such an effect of Ignatia amara on their locomotion (see below, the subsection relative to adaptation).

Table 2 Safety of the homeopathic drug, Ignatia amara

\begin{tabular}{|c|c|c|}
\hline Traits & Control = normal diet & Diet with Ignatia amara \\
\hline Linear speed (mm/sec) & $11.4(10.1-12.6)$ & $10.4(9.7-12.2)$ \\
\hline Angular speed (ang.deg./cm) & $\mid 28(|| 0-|4|)$ & $135(|15-| 54)$ \\
\hline Orientation (ang.deg) & $33.9(26.2-45.6)$ & $(51.6(36.1-67.1)$ \\
\hline Audacity $\left(n^{\circ}\right)$ & $2.10[1-3]$ & $2.75[2-4]$ \\
\hline \multicolumn{3}{|l|}{ Tactile perception: } \\
\hline Linear speed & $5.3(4.9-6.1)$ & $8.2(7.3-9.1)$ \\
\hline Angular speed & $275(242-314)$ & $176(160-194)$ \\
\hline Brood caring $\left(n^{\circ} / 10\right)$ & 0 & 2 \\
\hline \multicolumn{3}{|l|}{ Aggressiveness: } \\
\hline Against nestmates (a) & 0.11 & 0.24 \\
\hline Against aliens (a) & 4.38 & 4.51 \\
\hline Escape behavior $\left(\mathrm{n}^{\circ} / \mathrm{n}^{\circ}\right)$ & $8 / 12=0.66$ & $6 / 12=0.50$ \\
\hline \multicolumn{3}{|l|}{ Cognition: } \\
\hline Small area $\left(n^{\circ}\right)$ & 5 & 20 \\
\hline Large area $\left(n^{\circ}\right)$ & 8 & 0 \\
\hline Short term memory & $90 \%$ & $70 \%$ \\
\hline \multicolumn{3}{|l|}{ Adaptation: } \\
\hline Linear speed (mm/sec) & - & $10.6(8.8-|| .7)$ \\
\hline Angular speed (ang.deg./cm) & - & $179(\mid 59-200)$ \\
\hline
\end{tabular}

Experimental details and statistics are given in the text. Briefly, Ignatia amara decreased the ants' orientation ability, tactile perception, cognition and memory; it decreased the ants' brood caring behavior and induced some aggressiveness between nestmates, affecting thus the social relationships. No adaptation to these adverse effects of the homeopathic drug occurred. Ignatia amara appeared thus to be not entirely safe. 
Orientation to an alarm signal: This trait was affected by Ignatia amara consumption (Table 2, line 3; Figure 1(A1, A2)). While ants under normal diet oriented themselves very well towards a tied nestmates, when consuming Ignatia amara, they did so rather and statistically significantly less well $\left(\chi^{2}=14.19, \mathrm{df}=2, \mathrm{P}<0.001\right)$. This was obvious to observers: all occurred as if ants were less sensitive to an alarm signal or were less able to reach such a signal while consuming Ignatia amara. This may be due to some decrease of perception and/or cognition, two presumptions checked by two following experiments (see below, the subsections 'Tactile perception' and 'Cognition').

Audacity: This trait was increased by Ignatia amara consumption (Table 2, line 4; Figure 1(B1, B2)), but not significantly, probably due to the smallness of the sample $(\mathrm{N}=5, \mathrm{~T}=13.5, \mathrm{P}=0.078)$. Under Ignatia amara diet, the ants seemed to be less aware of the presence of a danger, and were thus more inclined to move on a risky apparatus, an observation in agreement with the previously observed ants' lower response to an alarm signal (see above, the subsection on orientation).

Tactile (pain) perception: Ignatia amara appeared to decrease the ants' tactile perception (Table 2, lines 5, 6; Figure $1(\mathrm{C} 1, \mathrm{C} 2)$ ). Indeed, while ants under normal diet moved very slowly and sinuously on a rough substrate, ants consuming this drug moved there not so slowly and sinuously, and such differences were statistically significant (linear speed: $\chi^{2}=24.00, \mathrm{df}=1, \mathrm{P}<0.001$; angular speed: $\chi^{2}=28.44$, $\mathrm{df}=2, \mathrm{P}<0.001$ ). This decrease of perception was in agreement with the ants' lower ability in reaching a source of alarm pheromone (see the above subsection on orientation).

Brood caring behavior; This social behavior was somewhat decreased by Ignatia amar consumption (Table 2, line 7; Figure 1 $(\mathrm{D} 1, \mathrm{D} 2))$. The numbers of not re-enterred larvae, among ten ones removed from the nest, after 30s, 2, 4, 6, 8 and 10 minutes equaled 10 , $8,5,3,2,0$ respectively for ants under normal diet, and $10,9,7,6,4$, 2 respectively for ants consuming Ignatia amara. The difference of behavior between ants under one and the other kinds of diet was thus significant: $\mathrm{N}=5, \mathrm{~T}=15, \mathrm{P}=0.031$. In fact, ants consuming the drug not so promptly found and held the larvae, and not so rapidly found the nest entrance than while living under normal diet, what was in agreement with the impact of Ignatia amara on the ants' perception (see the above subsections on orientation and perception).

Aggressiveness against nestmates; Unexpectedly, this trait was a little impacted by Ignatia amara consumption (Table 2, line 8; Figure 1 (E1, E2)). Under normal diet, the ants exhibited 63, 73 and 15 times the levels 0 (doing nothing), 1 (antennal contact) and 2 (mandibles opening) of aggressiveness, while ants consuming Ignatia amara exhibited the same levels of aggressiveness 50, 81 and 31 times respectively. The difference of behavior between ants consuming or not the drug was significant: $\chi^{2}=6.55, \mathrm{df}=2, \mathrm{P}<0.05$. Observers could often seen ants consuming the homeopathic drug opening their mandibles while moving and encountering nestmates on their foraging area. Some lower perception of social odors may explain such behavior.

Aggressiveness against aliens:This trait was not statistically, though slightly changed, by Ignatia amara consumption (Table 2, line 9; Figure 1 F1, F2). Under normal diet, ants exhibited 14, 28, 74 72 and 38 times the levels $0,1,2,3$ (gripping) and 4 (stinging) of aggressiveness, while ants consuming Ignatia amara exhibited the same levels of aggressiveness 14,27, 53, 82 and 50 times respectively. Thus, under the homeopathic drug, the ants more promptly gripped and stung an alien, but their general aggressiveness did not statistically differed from that presented under normal diet $\left(\chi^{2}=5.78, \mathrm{df}=4,0.20\right.$
$<\mathrm{P}<0.30$ ). It can however be presumed, on the basis of the results related in this and the previous subsections, that ants consuming Ignatia amara may more easily become aggressive than ants living under normal diet.

5.1.8 Escaping behavior: Numerically, this trait was not impacted by Ignatia amara consumption (Table 2, line 10), but some behavioral differences appeared between ants under normal and the homeopathic drug diet (Figure $1(\mathrm{G} 1, \mathrm{G} 2)$ ). The numbers of ants still enclosed in the course of the 12 experimental minutes equaled $12,11,9,9,7$, 7, 4 for ants under normal diet, and 12, 11, 10, 9, 8, 7, 6 for ants consuming Ignatia amara: the difference was not significant; $\mathrm{N}=3$, NS. Of course, the numbers of ants escaped over the same time period equaled $0,1,3,3,5,5,8$ for ants under normal diet, and $0,1,2,3,4,5$, 6 for ants under the drug diet: the difference was also not significant; $\mathrm{N}=3$, NS. However, it appeared that ants consuming Ignatia amara were calm, walked along the rim of the enclosure, found (came just in front of) the exit, but not always and not quickly moved through the exit and went out of the enclosure. The ants seemed less worried by their enclosing and/or may have their cognition somewhat reduced, a presumption checked in the following experiment (see below).

Cognition: This trait was highly, statistically significantly impacted by Ignatia amara consumption (Table 1, lines 11, 12; Figure $1 \mathrm{H1}$, $\mathrm{H} 2$ ). Experimentally, on ants under normal diet, 30, 16, 13, 12, 10, 6 and 5 ants were successively counted in the small area of the apparatus in the course of the 12 experimental minutes. Experimentally, on ants under the drug diet, these successive numbers equaled 30, 23, 22, 20, 21,18 and 20. The ants' ability in crossing the twists and turns path of the apparatus was thus decreased by Ignatia amara $(\mathrm{N}=5, \mathrm{~T}=21$, $\mathrm{P}=0.016$ ). For ants under normal diet, $0,0,1,2,5,7$ and 8 ones were counted in the large area beyond the difficult path in the course of the 12 experimental minutes. For ants under the drug diet, these numbers equaled 0 (zero) for each successive time. The difference between ants under the two kinds of diet was thus significant: $\mathrm{N}=5, \mathrm{~T}=-15, \mathrm{P}$ $=0.031$. Observers could not but be surprised by the ants' (under the drug diet) failure in crossing the twists and turns path. Ignatia amara may thus severely impact the cognition.

Memory: This trait was affected by Ignatia amara consumption (Table 1, line 13; Figure 1 (I1, I2)), though not statistically significantly probably because the sample was too small $(\mathrm{N}=40)$. In fact, under normal diet, 18 ants gave the correct response and 2 ones the wrong response, and under the drug diet, 14 ants gave the correct response and 7 ants gave the wrong response. The difference between these two scores was thus not statistically significant: $\chi^{2}=2.11$, df $=1,0.10<\mathrm{P}$ $<0.20$. However, this result was in agreement with the previous one, allowing presuming some impact of Ignatia amara on the cognition, the brain activity and the central nervous system.

Adaptation to the adverse effect of Ignatia amara on the ants' locomotion: The ants did not adapted themselves to the impact of the homeopathic drug on their locomotion (and their health in general, very probably) (Table 1, lines 14, 15; Figure 3 (A, B, C)). After 8 days of Ignatia amara consumption, the ants' linear speed still remained a little and not statistically lower than the control one $\left(\chi^{2}=3.02, \mathrm{df}=2\right.$, $0.20<\mathrm{P}<0.30$ ), and was similar to, though a little lower than, that presented after one day of the drug consumption $\left(\chi^{2}=1.26, \mathrm{df}=2,0.50\right.$ $<\mathrm{P}<0.70)$. As for the ants' sinuosity, it was still statistically larger than the control one $\left(\chi^{2}=44.48, \mathrm{df}=2, \mathrm{P}<0.001\right)$ and was even statistically larger than that presented after 1 day of consumption $\left(\chi^{2}=26.18, \mathrm{df}=2\right.$, $\mathrm{P}<0.001)$. Consequently, the ants' locomotion became more and more impacted in the course of the Ignatia amara consumption. The other physiological and ethological traits affected by the drug might also 
be more and more affected in the course of time, what is not in favor of that drug use, except if such impacts are exactly what is required for treating some kinds of pathology. The following subsection on the drug efficiency examined this point of view.

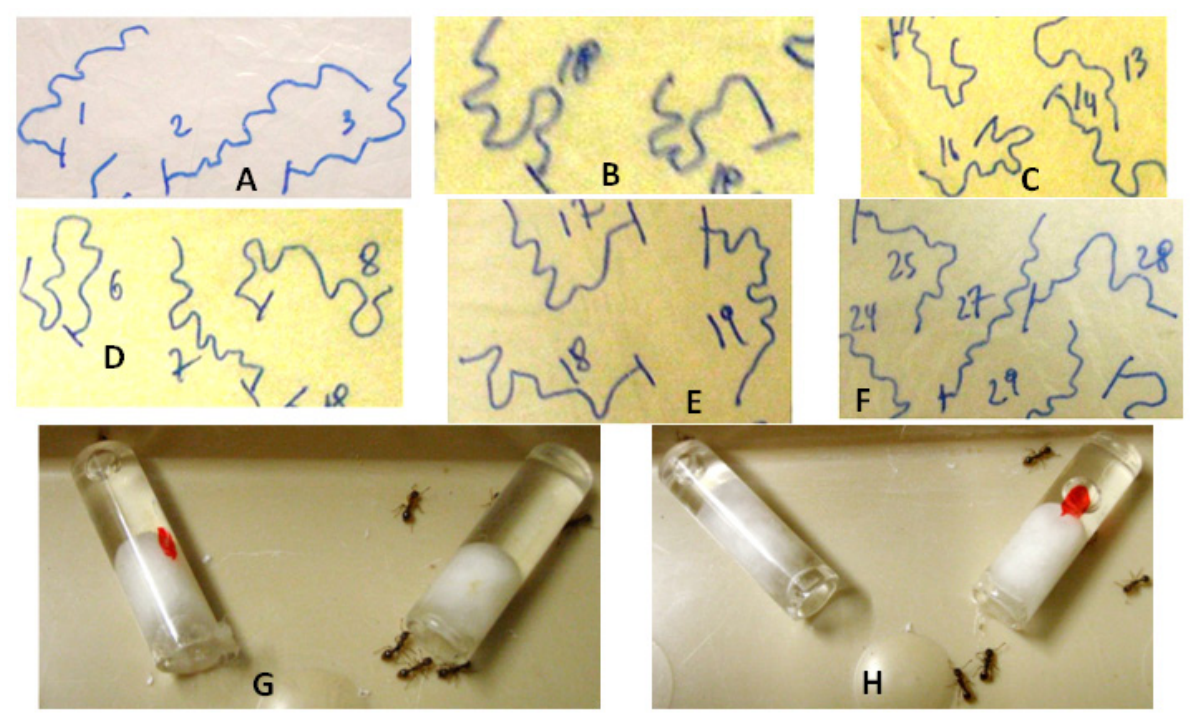

Figure 3 A- F: trajectories of ants being (A) under normal condition (no odor, no drug), (B) without odor under a diet with lgnatia amara since one day, (C) without odor under a diet with Ignatia amara since eight days, (D) in presence of onion odor under normal diet, (E) in presence of onion odor under a diet with Ignatia amara since one day, $(\mathbf{F})$ in presence of onion odor under a diet with Ignatia amara since eight days. Ignatia amara impacted the ants' locomotion (B) and ants did not adapt themselves to that adverse effect (C). Onion impacted the ants' locomotion (D), Ignatia amara decreased this effect (E) and ants did not habituate themselves to that beneficial effect $(\mathbf{F})$ (trajectories seen in $\mathbf{F}$ resemble those seen in $\mathbf{A})$. $\mathbf{G}$ (colony $\mathbf{A}), \mathbf{H}$ (colony $\mathbf{B})$ : two views of the experiments made for examining ants' potential dependence of Ignatia amara.Ants only very slightly and not at all significantly (see the text) preferred the liquid free of the drug, in presence of it and of a liquid with the drug (marked by a red point). They did not become dependence on lgnatia amara.

Efficiency of Ignatia amara (parts III and IV (Table I) of the work)

Effects of onion (part III (Table 1) of the work): $\quad$ For this subsection, the controls were the results obtained on ants living under normal diet, without onion in their trays, i.e. the controls used in the previous subsections.

Linear and angular speeds: Onion impacted these traits (Table 3, lines 1,2). In presence of onion odor, the ants walked somewhat more

Table 3 Efficiency of the homeopathic drug, Ignatia amara quickly $\left(\chi^{2}=13.35, \mathrm{df}=2,0.001<\mathrm{P}<0.01\right)$ and largely more sinuously $\left(\chi^{2}=18.15, \mathrm{df}=2, \mathrm{P}<0.001\right)$. Ants seemed to be nervous, perturbed by the onion odor.

Orientation to an alarm signal: This ability was reduced by onion odor (Table 3, line 3; Fig. 2 A1A2). While in absence of onion the ants very well oriented themselves to a tied nestmate, in presence of that odor, they badly did so, a deficiency statistically significant $\left(\chi^{2}\right.$ $=28.95, \mathrm{df}=2, \mathrm{P}<0.001)$. Once more, the ants appeared to be perturbed by the onion odor.

\begin{tabular}{lll}
\hline Traits & Onion on the ants' area, normal diet & Onion on the ants' area, diet with Ignatia amara \\
\hline Linear speed $(\mathrm{mm} / \mathrm{sec})$ & $12.8(\mid 1.8-14.2)$ & $12.1(10.8-13.6)$ \\
Angular speed (ang.deg./cm) & $157(134-179)$ & $127(98-141)$ \\
Orientation (ang.deg) & $65.4(40.6-87.7)$ & $46.1(37.5-63.9)$ \\
Audacity $\left(\mathrm{n}^{\circ}\right)$ & $1.65[0-3]$ & $2.40[1-3]$ \\
Tactile perception: & & \\
Linear speed & $8.7(8.3-9.2)$ & $6.3(5.0-6.8)$ \\
Angular speed & $135(110-166)$ & $253(217-266)$ \\
Brood caring $\left(\mathrm{n}^{\circ} / 10\right)$ & 4 & 0 \\
Aggressiveness: & & 0.14 \\
Against nestmates $(\mathrm{a})$ & 0.69 & 4.8 \\
Against aliens $(\mathrm{a})$ & 4.44 & $9 / 12=0.75$ \\
Escape behavior $\left(\mathrm{n}^{\circ} / \mathrm{n}^{\circ}\right)$ & $7 / 12=0.58$ & \\
\hline
\end{tabular}


Table Continued...

\begin{tabular}{lll}
\hline Traits & Onion on the ants' area, normal diet & Onion on the ants' area, diet with Ignatia amara \\
\hline Cognition: & 15 & 8 \\
Small area $\left(\mathrm{n}^{\circ}\right)$ & 2 & 11 \\
Large area $\left(\mathrm{n}^{\circ}\right)$ & $50 \%$ & $60 \%$ \\
Short term memory & & \\
Adaptation: & - & $11.9(110-128)$ \\
Linear speed $(\mathrm{mm} / \mathrm{sec})$ & - & $179(103-136)$ \\
Angular speed $($ ang.deg./cm) & & \\
\hline
\end{tabular}

Experimental details and statistics are given in the text. The results given in the second column are to be compared to those given in the second column of Table 2. Briefly, onion odor increased the ants' sinuosity, decreased their linear speed, orientation ability, tactile perception, escaping behavior, cognition and memory. It decreased their brood caring behavior and induced some aggressiveness between nestmates, impacting so the social relationships. Ignatia amara, given to ants affected by onion odor, reduced the ants' sinuosity and aggressiveness against nestmates, nearly restored their orientation, audacity, tactile perception, brood caring, escape behavior, cognition and improved their memory. The ants presented no habituation to these beneficial effects of the homeopathic drug.

Audacity: Onion odor slightly, not significantly, decreased this ethological trait (Table 3, line 4; Figure 2(B1; $\mathrm{N}=5)$ ), $\mathrm{T}=-11.5, \mathrm{P}$ $=0.187$ ). It was obvious to observers that ants were more perturbed by the pieces of onion than by the presence of an unknown apparatus on their foraging area, and consequently came on it less often than in the absence of onion.

Tactile (pain) perception: This physiological trait was affected by onion odor (Table 3, lines 5, 6; Figure $2 \mathrm{C} 1$ ). In the absence of that odor, the ants walked very slowly and sinuously on a rough substrate; in the presence of that odor, they walked not so slowly and less sinuously on such a substrate, and this difference was statistically significant (linear speed: $\chi^{2}=34.28, \mathrm{df}=, \mathrm{P}<0.001$; angular speed: $\chi^{2}$ $=39.00, \mathrm{df}=2, \mathrm{P}<0.001)$. In fact, the ants were more perturbed by the onion odor than by the rough character of the substrate.

Brood caring behavior: Onion odor affected this social task (Table 3 , line 7; Figure 2 (D1)). Without pieces of onion on the ants' tray, the numbers of not re-entered larvae after 30s, 2, 4, 6, 8 and 10 minutes equaled $10,8,5,3,2$ and 0 respectively. With such pieces in the ants' tray, these numbers equaled $10,10,8,8, \mathrm{n} 6$ and 4 respectively. The difference of behavior between ants under one and the other kinds of situation was thus significant: $\mathrm{N}=5, \mathrm{~T}=15, \mathrm{P}=0.031$. In fact, in the presence of onion odor, the ants delayed in finding and holding the larvae, as well as in reaching the nest entrance, being obviously perturbed by the onion odor.

Aggressiveness against nestmates: This social relationship was affected by onion odor (Table 3, line 8; Figure 2 (E1)). Without onion odor, ants presented $63,73,15$ and 0 times the levels of aggressiveness 1 (doing nothing), 2 (antennal contact), 3 (mandibles opening) and 3 (gripping). In the presence of onion, they presented these four levels of aggressiveness 29, 61, 61 and 1 times respectively. This difference of behavior between ants under one and the other kinds of situation was significant $\left(\chi^{2}=42.60\right.$, df $\left.=3, \mathrm{P}<0.001\right)$. Onion odor induced thus some slight (mandibles opening essentially) aggressiveness between nestmates, affecting thus their social relationship, a results in agreement with that relative to the ants' brood caring behavior (see just above).

Aggressiveness against aliens: This behavior was very slightly and not statistically significantly modified by onion odor (Table 3 , line 9 ; Figure 2(F1)). In the absence of onion odor, the ants presented 14, 28, 74, 72 and 38 times the levels of aggressiveness $0,1,2,3$ and 4 (stinging) respectively. In presence of that odor, they presented these levels of aggressiveness 11, 28, 61, 58 and 54 times respectively. They thus sooner and more often gripped and stung the aliens. However, their general aggressiveness did not statistically differ from that exhibited in the absence of onion odor $\left(\chi^{2}=5.47, \mathrm{df}=4,0.20<\mathrm{P}<0.30\right)$.

Escaping behavior: This trait was affected by onion odor (Table 3, line 10; Figure 2 (G1)). Without that odor, the numbers of ants escaped in the course of the 12 experimental minutes equaled 0,1 , $3,3,5,5$ and 8 respectively (and of those not escaped 12, 11, 9, 9, 7, 7 and 4 respectively). In the presence of onion odor, these numbers equaled respectively $0,0,2,3,4,4$ and 7 (escaped ants), as well as $12,12,10,9,8,8$ and 5 (not escaped ants). The difference of escaping ability between ants experimented under the two kinds of situation was statistically significant (ants escaped: $\mathrm{N}=5, \mathrm{~T}=-15, \mathrm{P}=0.031$; ants not escaped: $\mathrm{N}=5, \mathrm{~T}=15, \mathrm{P}=.031$ ). In presence of onion odor, the ants seemed perturbed and therefore failed in finding the exit, but they also somewhat failed in moving through the exit when they found it. Their cognition might thus be somewhat impacted by the odor of onion, a presumption checked by the following experiment (see just below).

Cognition: Onion odor impacted this physiological trait (Table 3, line 11; Figure 2 H1). Without that odor, 30, 16, 13, 12, 10, 6 and 5 ants were successively over time counted in the small area in front of the twists and turns path, while $0,0,1,2,5,7$ and 8 were counted during the same time periods in the large area beyond the difficult path. In presence of onion odor, these numbers were respectively $28,25,22$, $21,19,16$ and 15 (small area), as well as $0,0,0,0,0,1$ and 2 (large area). The difference of performance between ants under the two kinds of situation was significant (small area: $\mathrm{N}=6, \mathrm{~T}=21, \mathrm{P}=0.016$; large area: $\mathrm{N}=5, \mathrm{~T}=-15, \mathrm{P}=0.031$ ). Onion odor affected thus the ants' cognition and so, probably, their brain functioning. This hypothesis was checked in the next experiment (see just below).

Memory: This trait was affected by onion odor (Table 2, line 12; Fig. 2 I1). Without that odor, the ants, trained to a green hollow cube, reached a conditioning score of $60 \%, 70 \%, 75 \%, 80 \%, 85 \%$ and $90 \%$ after 7, 24, 31, 48, 55 and 72 hours respectively. In presence of that odor, the ants, trained to a yellow hollow cube, reached, after the same time periods, the conditioning scores of $50 \%, 50 \%, 55 \%, 55 \%$, $60 \%$ and $50 \%$ respectively. The difference of reached conditioning scores between the ants living under the two kinds of situation was statistically significant: $\mathrm{N}=6, \mathrm{~T}=-21, \mathrm{P}=0.016$. Consequently, in presence of onion odor, the ants poorly memorized the visual cue associated with their food.

Notes: All the results here above reported as for the impact of onion odor on the ants' physiology and ethology are in concordance 
with those previously found in a work devoted to the impact of environmental odor. ${ }^{35}$

It was thus found that onion affected several ants' physiological and ethological traits because it caused nervousness, perturbation, and stress. Could Ignatia amara remove or at least reduce such impacts of onion odor? Answering this question was the aim of the following and last subsection of the results section.

Efficiency of Ignatia amara (part IV (Table 1) of the work: Note: The results related in this subsection were obtained without looking to those obtained in the course of the preceding experiments, i.e. being blind to the situations

Linear and angular speeds: Ignatia amara appeared to ameliorate these traits affected by onion odor (Table 3, lines 1, 2). In presence of onion and living under a diet with this homeopathic drug, the ants presented a linear speed slightly smaller than that presented in presence of onion odor under a normal diet, but this change of linear speed was not significant $\left(\chi^{2}=4.32, \mathrm{df}=3,0.20<\mathrm{P}<0.30\right)$. However, in presence of onion odor and under a diet with Ignatia amara, the ants' linear speed was very similar to, not statistically different from the control one (i.e. that presented under normal diet in the absence of onion odor) $\left(\chi^{2}=3.19, \mathrm{df}=3,0.30<\mathrm{P}<0.50\right)$. The homeopathic drug had thus a slight beneficial effect on ants affected by onion odor. As for the ants' sinuosity, Ignatia amara largely decreased it while it was enlarged by onion odor, and this decrease was highly statistically significant $\left(\chi^{2}=21.07, \mathrm{df}=3, \mathrm{P}<0.001\right)$. The sinuosity of ants living in presence of onion odor and under a diet with Ignatia amara was similar to the control one, i.e. with no statistical difference compared to that presented in absence of onion odor and under normal diet $\left(\chi^{2}=1.53, \mathrm{df}=3,0.50<\mathrm{P}<0.70\right)$. Consequently, even if increasing the sinuosity of ants living under normal situation, when consumed in a stressing situation (e.g. in presence of onion odor), Ignatia amara reduced a trait enlarged by the stress, reduced the sinuosity enlarged by the onion odor, and made it similar to the control one. This effect was unexpected and was obvious to the observed.

Orientation to an alarm signal: This trait, impacted by onion odor, was somewhat ameliorated by Ignatia amara consumption (Table 3, line 3; Figure 2 (A1A2)). In presence of onion odor and under normal diet, the ants poorly reached a tied nestmate. In presence of that odor and under a diet with Ignatia amara, the ants better reach such a nestmate, the difference of orientation ability between ants under the two kinds of condition being at the limit of significance $\left(\chi^{2}=7.48\right.$, $\mathrm{df}=3,0.05 \sim \mathrm{P}<0.10)$. The orientation ability of ants in presence of onion odor and under a diet with the homeopathic drug was nearly statistically significantly similar to the control one $\left(\chi^{2}=5.50, \mathrm{df}=2\right.$, $0.50 \sim \mathrm{P}<0.10$ ). It could thus be concluded that Ignatia amara was not without effect but induced some recovering by ants of their instinctive capability to orient themselves towards a source of alarm pheromone, though they not yet fully acquired again the capability they had under normal condition.

Audacity: Ignatia amara increased the audacity of ants living under onion odor (Table 3, line 4; Figure (2B1, B2)). Indeed, more ants consuming that homeopathic drug and living in presence of onion odor were counted on the unknown apparatus than ants living in presence of that odor and not consuming Ignatia amara. However, the difference of audacity between the ants living under the two kinds of situation was not significant due to the smallness of the sample $(\mathrm{N}=3$, NS). However, the audacity of ants consuming Ignatia amara in presence of onion odor was statistically similar to that of ants living under normal condition $(\mathrm{N}=5, \mathrm{~T}=11, \mathrm{P}=0.219)$. The homeopathic drug appeared thus to reinforce the ants' audacity somewhat reduced by the onion odor, an observation at the limit of significant (see just above).

Tactile (pain) perception:This ants' physiological trait, decreased in presence of onion odor, appeared to be no longer reduced when ants consumed Ignatia amara (Table 3, lines 5, 6; Figure $2(\mathrm{C} 1, \mathrm{C} 1)$ ). The ants' locomotion on a rough substrate, characterized by a low linear speed and a large sinuosity in presence of onion odor under normal diet, became no longer so slow and sinuous when ants consumed Ignatia amara in presence of that odor. This change was statistically significant (linear speed: $\chi^{2}=19.36, \mathrm{df}=3, \mathrm{P}<0.001$; angular speed: $\left.\chi^{2}=32.25, \mathrm{df}=2, \mathrm{P}<0.001\right)$. Moreover, the ants' locomotion on a rough substrate in presence of onion odor and under a diet with the homeopathic drug appeared to be similar to that presented on a rough substrate without odor and under normal diet (linear speed: $\chi^{2}=1.21$, $\mathrm{df}=1,0.20<\mathrm{P}<0.30$; angular speed: $\chi^{2}=3.91, \mathrm{df}=2,0.10<\mathrm{P}<0.20$ ). Ignatia amara had thus the effect of restoring the ants' perception decreased by onion odor.

Brood caring behavior: This trait, impacted by onion odor, was improved by Ignatia amara consumption (Table 3, line 7; Figure 2 (D1D2)). While under normal diet in presence of onion odor, ants presented difficulties in re-entering the larvae removed from the nest (successive numbers of not re-entered larvae: 10, 10. 8, 8, 6 and 4), when consuming the homeopathic drug in presence of onion odor, they well and promptly re-interred the larvae (successive numbers of not re-entered larvae: 10, 8, 6, 4, 2 and 0 ). The difference of brood caring between the ants living under the two kinds of situation was statistically significant $((\mathrm{N}=5, \mathrm{~T}=-15, \mathrm{P}=0.031)$. Moreover, the difference of brood caring between ants living under normal diet without odor (successive numbers of not re-entered larvae: 10, 8, 5, 3,2 and 0 ) and ants living in presence of onion odor and under a diet with Ignatia amara was not significant $(\mathrm{N}=2$, NS). The homeopathic drug restored thus the ants' brood caring behavior affected by the stressing onion odor.

Aggressiveness against nestmates: Ignatia amara had an impact on this ethological trait (Table 3, line 8, Figure 2 (E1, E2)). In presence of onion odor under normal diet, the ants presented some aggressiveness against nestmates, having made during the experimental encountering 29, 61, 61 and 1 times the levels 0 (doing noting), 1 (antennal contacts), 2 (mandibles opening) and 3 (gripping) of aggressiveness. In presence of onion odor under a diet with Ignatia amara, the ants were less aggressive towards their nestmates, having made during the encountering 68, 69, 20 and 0 times the same levels of aggressiveness. The difference of aggressiveness between ants tested under the two kinds of situation was highly significant: $\chi^{2}=38.77, \mathrm{df}=2, \mathrm{P}<0.001$. Also, the aggressiveness of ants in presence of onion odor under a diet with Ignatia amara was statistically similar to that of ants tested under control condition and having made during the tests $63,73,15$ and 0 times the levels $1,2,3$ and 4 of aggressiveness respectively $\left(\chi^{2}=0.73\right.$, $\mathrm{df}=2,0.50<\mathrm{P} \sim 0.70$ ). Ignatia amara reduced thus the ants' slight aggressiveness against nestmates induced by onion odor.

Aggressiveness against aliens: This trait remained as before under a diet with Ignatia amara (Table 3, line 9, Figure 2 (F1, F2)). In presence of onion odor under a normal diet, the ants presented 11, 28, 61, 58 and 54 times the levels of aggressiveness $0,1,2,3$ and 4 (stinging). In presence of onion odor under a diet with Ignatia amara, they presented these levels 9,27,59, 76 and 38 times respectively. The difference of behavior between the ants under one and the other kinds of situation was not significant: $\chi^{2}=5.42, \mathrm{df}=4,0.20 \sim \mathrm{P}<0.30$. Additionally, the behavior of ants in presence of onion odor under a diet with the homeopathic drug no longer differed from that of 
ants under normal condition which presented 14, 28, 74, 72 and 38 times the levels of aggressiveness $0,1,2,3$ and 4 respectively. The difference between these two series of recorded numbers was not at all significant: $\chi^{2}=2.23, \mathrm{df}=4,0.50<\mathrm{P} \sim 0.70$. Consequently, even if Ignatia amara had some calming effect on ants being in presence of onion odor, it did not affect their usual, normal aggressiveness against aliens, a fact already pointed out in the previous subsection relative to the effect of that drug (see above).

Escaping behavior: Ignatia amara appeared to improve this trait affected by onion odor (Table 3, line 10; Figure 2 (G1, G2)). In presence of onion odor and under normal diet, the numbers of ants still enclosed in the course of the 12 experimental minutes equaled $12,12,10,9,8,8$ and 5 successively, and of those escaped equaled 0 , $0,2,3,4,4$ and 7 successively. In presence of onion odor and under a diet with Ignatia amara, these numbers equaled 12, 10, 9, 8, 7, 5 and 3 ants still enclosed, as well as $0,2,3,4,5,7$ and 9 ants escaped. The difference of escaping behavior between ants experimented under the two kinds of situation was statistically significant: $\mathrm{N}=6, \mathrm{~T}=-21$ (ants enclosed) +21 (ants escaped), $\mathrm{P}=0.016$. Also, the escaping behavior of ants living in presence of onion under a diet with Ignatia amara was slightly of better quality than that of ants living without odor and a normal diet: $\mathrm{N}=4, \mathrm{~T}=-10$ (ants : enclosed), +10 (ants escaped), $\mathrm{P}=0.063$ ). The homeopathic drug had thus an effect on the stressed ants: it allowed them to be again able to soon escape from an enclosure. Such an effect was similar to that found for an extract of four plants used by humans for feeling calmer and sleeping better, an extract the effects of which we previously examined on ants. ${ }^{48}$

Cognition: Ignatia amara largely ameliorated the cognition decreased by onion odor (Table 3, lines 11, 12; Figure $2(\mathrm{H} 1, \mathrm{H} 2)$ ). In presence of onion odor under normal diet, over the 12 experimental minutes, $28,25,22,21,19,16$ and 15 ants were successively counted in the small area in front of the twists and turns path, and $0,0,0,0,0,1$ and 2 ants were successively counted in the large area beyond the difficult path. In presence of onion odor under a diet with Ignatia amara, these two series of counts were $25,23,16,16,15,12$ and 11 ants as well as $0,0,1,3,5,7$ and 8 ants. The difference of counted ants between those tested under one and the other kinds of condition were statistically significant: small area: $\mathrm{N}=7, \mathrm{~T}=-28, \mathrm{P}=0078$; large area: $\mathrm{N}=5, \mathrm{~T}=15, \mathrm{P}=0.031$. The homeopathic drug improved thus the ants' cognition reduced by onion odor. Was the ants' cognition in presence of onion odor under a diet with Ignatia amara identical to the control one, i.e. that without odor under normal diet? For the small area in front of the difficult path, the control numbers were $30,16,13$, $12,10,6$ and 5 . There was thus still a small difference between the ants' cognition under control condition and under "onion odor + diet with Ignatia amara" situation, but this difference was small and just below the limit of significance $(\mathrm{N}=7, \mathrm{~T}=-3.5,+24.5, \mathrm{P}=0.047)$. Also, concerning the ants counted in the large area beyond the difficult path, the control numbers were $0,0,1,2,5,7$, and 8 successively, and were thus identical to those obtained for ants in presence of onion odor under a diet with Ignatia amara $(\mathrm{N}=1, \mathrm{NS})$. The same numbers of ants reached the large area. It could thus be concluded that the homeopathic drug nearly completely restored the ants' cognition impacted by onion odor.

Memory: This trait, which was the first examined after having given again the homeopathic drug to the ants, was very slightly and not statistically significantly ameliorated by that drug. Indeed, in presence of onion under normal diet, the ants presented a conditioning score of $50 \%$, then, in presence of onion under a diet with Ignatia amara, they presented a score of $60 \%$ (Table 3, line 13; Figure 2 (I1, I2)). However, the difference between these two conditioning scores was not significant: $\chi^{2}=0.11, \mathrm{df}=1,0.70<\mathrm{P}<0.80$. Ignatia amara had thus a beneficial effect on the ants' memory, but this effect was weak and not significant. Note that the sample used was small $(\mathrm{N}=40)$. With repeated experiments or more experimented animals, the effect of the homeopathic drug may become larger and significant.

Habituation to potential beneficial effects of Ignatia amara: Ants did not habituate themselves to the effects of Ignatia amara, at least to the effect on their locomotion (Table 3, lines 14, 15; Figure 3 (D-F)). In presence of onion odor under a diet with Ignatia amara, the ants moved not so quickly as in presence of onion odor under normal diet, the difference being at the limit of significance $\left(\chi^{2}=7.51, \mathrm{df}=3,0.10\right.$ $<\mathrm{P} \sim 0.05)$, and largely less sinuously, the difference being highly significant $\left(\chi^{2}=24.86, \mathrm{df}=3, \mathrm{P}<0.001\right)$. In fact, the ants moved as under normal condition, i.e. without odor and under normal diet, the difference of locomotion between ants living under these two kinds of situation being not at all significant (linear speed: $\chi^{2}=2.36, \mathrm{df}=3$, $\mathrm{P} \sim 0.50$; angular speed: $\chi^{2}=0.95, \mathrm{df}=3,0.80<\mathrm{P}<0.90$ ). Note that we recorded and analyzed the trajectories of ants in presence of onion odor under a diet with Ignatia amara being blind as for the results previously obtained for the ants' locomotion. It could thus be concluded that the homeopathic drug did not lead to habituation, what is in favor of its use.

Potential dependence on Ignatia amara consumption: No ants' dependence at all occurred on Ignatia amara consumption (Figure 3 $\mathrm{G}, \mathrm{H}$ ). During the experiments (in the course of which the ants were calm), 18 ants of colony A were counted on the sugar water containing Ignatia amara and 22 ones on the sugar water free of that drug. At the same time, 23 ants of colony B were counted on the sugar water containing the drug and 14 ones on the sugar water free of it. In total, 41 ants have thus chosen the liquid containing Ignatia amara and 36 ants the liquid which did not contain that drug. These two numbers (41 and 36) did not statistically differ from those expected if ants had randomly gone onto each liquid ( 38.5 and 38.5$)\left(\chi^{2}=0.058, \mathrm{df}=1,0.80\right.$ $<\mathrm{P}<0.90)$. On the basis of this result, it could be stated that Ignatia amara did not lead to any dependence in ants, what is in favor of a medicinal use of this product (Figure 4).
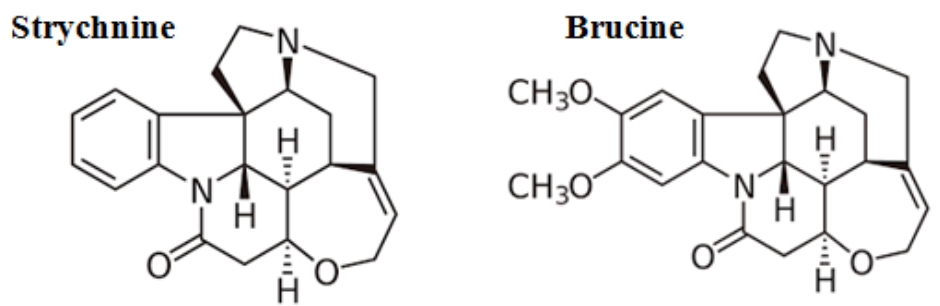

Figure 4 Chemical structure of strychnine and brucine, the two alkaloids present in the here studied homeopathic drug, lgnatia amara. Strychnine is the most present compound; brucine is present only in very small amount. At low dose, strychnine stimulates the central nervous system; at high dose, it is lethal. Brucine is less toxic and used in pharmacology. It is here examined if these compounds present in lgnatia amara are safe and efficient when used at the very low homeopathic doses. 


\section{Discussion}

The scientific community, in his vast majority, reject homeopathy as an efficient medical treatment, and consider that only the welldocumented placebo effect could be retained as the potential beneficial effect of any homeopathic drug. Nevertheless, the population, and many general practitioners still consider homeopathy as an effective way - at least in some cases - to treat patients. Numerous university faculties still teach homeopathy, but some ones have currently stopped to do so, and some national healthcare systems have stopped the reimbursements of homeopathic drugs. The questions are: is homeopathy really efficient? Is it without adverse effects? Has it only a placebo effect? Aiming to answer these questions, we examined the physiological and ethological effects of a given homeopathic drug (i.e. Ignatia amara, advised for treating anxious, nervous, stressed persons), on ants used as biological models, insensitive to the placebo effect. We worked in two successive times: we first studied the safety of that drug on ants maintained in normal conditions; then we examined its efficiency on ants experiencing a "stressful situation", generated by the presence in their environment of pieces of onion, which released aggressive chemical compounds. When starting this experimental work, we really thought that homeopathy was an inefficient alternative medicine, leading only to placebo effect, and susceptible to be somewhat dangerous since patients using it do not resort to scientifically-based medicine and are thus not correctly treated.

We found that Ignatia amara, consumed under normal conditions, decreased the ants' orientation ability, tactile perception, cognition, memory, brood caring behavior and induced some aggressiveness between nestmates, affecting thus their social relationships. Moreover, the ants did not adapt themselves to these harmful effects. Consequently, Ignatia amara seems to have some negative effects on ants' traits, so to says, is not perfectly "safe". We verified that onion odor set ants under a stressful situation, and indeed this odor increased the ants' sinuosity, decreased their linear speed, orientation ability, tactile perception, escaping behavior, cognition, memory, brood caring behavior and induced some aggressiveness between nestmates, impacting thus their social relationships. Note that these results on onion are in agreement with those previously obtained. ${ }^{44}$ After that, on ants maintained in presence of onion and under a diet with Ignatia amara, we unexpectedly found that this product - statistically! reduced the adverse effects of onion odor, and allowed ants to regain, physiologically and ethologically, the same traits levels as under normal diet (without onion odor). This looked somewhat similar to what was observed when giving to ants a diet with an extract of four plants what had on them a calming effect. ${ }^{39}$

How can we explain our results? First, using ants as model organisms, the placebo effect should not exist; therefore our observations cannot be explained by the placebo effect. Secondly, the small size of our experimental samples, in terms of numbers of individual ants tested, may explain that a difference between the control and the test situation for a given measured trait appeared as statistically significant even if, in reality, that should not be the case. However, we took the precaution to use non- parametric tests as well as similar batch as in our numerous previous experimental works, in order to avoid this risk of statistical misleading results.

Thirdly, the Ignatia amara tablets contain very small amounts of glucose and saccharose as well as of ethanol. However, these tablets are given as solutions in the ants' usual sugar water (what allows eliminating any effects of glucose and saccharose), and ants produce ethanol in their Dufour gland, the content of which is continuously deposited on the foraging area (what allows eliminating, at least partly, any effect of ethanol). Ignatia amara contains, in infinitesimal doses, two active compounds, i.e. two alkaloids, strychnine (highly efficient) and brucine (less efficient). These two alkaloids act on the central nervous system, ranging from sedative and tranquilizing effect to total paralysis. Injected to mice (several doses and times having been tested), some doses of strychnine were found to facilitate learning by affecting neurobiological processes underlying memory storage. ${ }^{49}$ Brucine is used in medicine, and its toxicity is thus examined. ${ }^{50} \mathrm{In}$ homeopathy, these two alkaloids are used (via the extract of the plant Ignatia amara) in extremely low amounts. The here used dilution, identical to that advised for humans, was a relatively small level of dilution. A few active molecules could have been thus present in the ants' sugar water containing the drug. The ants could therefore have reacted to these molecules, maybe because of a superior sensitivity to this kind of chemical compounds, but this remains hypothetical. In the absence of the stressing factor, the ants presented some slight physiological and ethological perturbations. They maybe reacted to the presence of toxic substances in their food. In presence of a stressing factor (onion odor), and when consuming the used dilution of Ignatia amara, the ants became "calmer" and had their physiology and ethology somewhat "restored" at a similar level as in the control batch. Even if we are still unable to explain our observations and explicit the very deep causes of the statistical differences we observed between control and test situations, we report here what looks like a slight beneficial effect of an homeopathic drug on ants physiological and ethological traits. This experimental work highlights the need of setting up more studies on model organisms which are insensitive to the placebo effect and the need to work on samples of large size. As a scientific precaution, we don't have to consider our results as a definitive statement on the safety or efficiency of homeopathic drugs. However, and taking into account all the necessary precaution when it comes to extrapolate results obtained on any model organism to humans, we could hypothesize that homeopathy might be useful in cases of some health problems. Also, as stated in any information, drugs notices and internet sites on the subject, homeopathic treatments must always be adapted to the individual. They depend on the cause(s) of the health problem as well as on the patient's physiology and psychology. No given generalization can be stated. However, some general indication can be given. For instance, for Ignatia amara, and considering our experimental results, it can be stated that this homeopathic drug could be of some help for patients suffering from stress, anxiousness, sleeping problems, depression, headache, stomach pain, and any disorders due to annoyance, and that this treatment will not reach to any harmful side-effects.

\section{Conclusion}

On basis of our experimental results on ants and considering our bibliographical review, we cautiously conclude that in given cases, for some precisely defined health problems, homeopathic drugs, adequately chosen, used in appropriate doses and under medical advice, could release patients from some health or psychological troubles, and help them to feel better. If it appears that homeopathic treatment can be considered as at least slightly beneficial and without any harmful side-effects, the use of homeopathic drugs could allow solving at least partly the health problems of patients, and maybe avoiding to use or abuse of strong medicinal drugs, these ones potentially leading to dependence. Therefore, it appears relevant to conduct more studies on the safety and the potential efficiency of homeopathic treatments, based on organisms insensitive to the placebo effect with the aim of 
reaching a deeper understanding of the potential biological effect of the infinitesimal doses of active molecules contained in homeopathic drugs. We thus consider this paper as one of these contributing studies.

\section{Acknowledgments}

We are very grateful to $\mathrm{Mr}$ J. Surbeck and Mr A. Fauteux for their advices and information, as well as to Dr R. Cammaerts for his help throughout the entire realization of the present paper

\section{Conflict of interests}

We affirm having no conflict of interest concerning the use of homeopathy in medicine and the selling of homeopathic products in drugstore. We are biologists, ecologists and ethologists, working essentially on ants, we receive no money for conducting our research and we are not related with any kind of pharmaceutical or parapharmaceutical company or industry.

\section{References}

1. Shang A, Huwiler-Müntener K, Nartey L, et al. Are the clinical effects of homeopathy placebo effects? Comparative study of placebo-controlled trials of homeopathy and allopathy. The lancet. 2005;366(9847):726732 .

2. https://www.hri-research.org/wp-content/uploads/2015/07/NHMRCInformation-Paper-Mar2015.pdf

3. http://www.easac.eu/home/press-releases/detail-view/article/ homeopathy.html

4. http://sante.lefigaro.fr/article/l-appel-de-124-professionnels-de-la-santecontre-les-medecines-alternatives-

5. Stub T, Musial F, Kristoffersen A, et al. Adverse effects of homeopathy, what do we know? A systematic review and meta-analysis of randomized controlled trials. Complementary Therapies in Medicine. 2016;26:146163

6. National Health and Medical Research Council. Administrative Report: NHMRC Advice on the effectiveness of homeopathy for treating health conditions. Canberra: National Health and Medical Research Council; 2015.

7. National Health and Medical Research Council. NHMRC Information Paper: Evidence on the effectiveness of homeopathy for treating health conditions. Canberra: National Health and Medical Research Council, 2015 .

8. https://www.liberation.fr/checknews/2018/.../1-homeopathie-est-elleefficace 1620115

9. https://www.franceculture.fr/

10. https://www.huffingtonpost.fr/2018/03/20/lhomeopathie-est-elle-unefake-medecine-ce-que-disent-les-etudes-scientifiques_a_23390249/

11. http://www.blog-elsevier-masson.fr/.../efficacite-clinique-delhomeopathie-analyse-et-propo

12. Trent Medicines Information. Clinical evidence for homeopathy Specialist Pharmacy Service. Meicester and Regional Drug \& Therapeutic Centre: Newcastel; 2017.

13. National Health and Medical Research Council. Frequently asked questions arising from public consultation: NHMRC Advice on the effectiveness of homeopathy for treating health conditions. Canberra: National Health and Medical Research Council; 2015.

14. Danno K, Colas A, Masson JL, et al. Homeopathic treatment of migraine in children: results of a prospective, multicenter, observational study. $J$ Altern Complement Med. 2013;19(2):119-223.
15. Bellavite P, Marzotto M, Conforti A. Scientific criticism in homeopathy: need to test more than disputes. Int J Clin Pract. 2014;68(3):403-404.

16. martinwinckler.com/spip.php?article101

17. https://fr.wikipedia.org/wiki/Effet_placebo

18. Cammaerts MC, Cammaerts D. Physiological and ethological effects of fluoxetine, on ants used as biological models. Int J Biol. 2015;7(2):1-18.

19. Cammaerts MC, Cammaerts D. Potential harmful effects of Carbamazepine on aquatic organisms, a study using ants as invertebrate models. Int J Biol. 2015;7(3):75-93.

20. Cammaerts MC, Cammaerts R. Aspartame increases food demand and impacts behavior: a study using ants as models. Acta Biomed Scient. 2016;(3):9-23.

21. Cammaerts MC, Cammaerts R. Effect of glutamate monosodium on behavior and cognition; a study using ants as biological models. An Public Health Res. 2016;10.

22. Cammaerts MC, Cammaerts R. Safety of glucosamine, examined on ants as models. MOJ Biol Med. 2018;3(4):132-142.

23. https://www.santemagazine.fr/medecines-alternatives/approchesnaturelles

24. https://www.topsante.com/medecines-douces/homeopathiehttps://www. topsante.com/medecines-douces/homeopathie

25. https://www.pharmaciengiphar.com/medecines-naturelles/homeopathie

26. http://www.doctissimo.fr/sante/homeopathie/souches-homeopathiques/ ignatia-amara

27. https://www.medicament.com

28. http://pharmacieetnature.com/produit/1773-ignatia-amara-homeopathie. $\mathrm{htm}$

29. Zanolin E, Bellavite P. Effects of Ignatia amara in mouse behavioura models. Homeopathy. 2012;101(1):57-67.

30. https://fr.wikipedia.org/wiki/Strychnine

31. https://fr.wikipedia.org/wiki/Brucine

32. Sherwood L, Klandorf H, Yancey P. Physiologie animale. De Boeck superieur Editors, Belgium; 2016. pp. 904.

33. Wolf FW, Heberlein U. Invertebrate models of drug abuse. $J$ Neurobiol. 2003;54(1):161-178.

34. Andre RG, Wirtz RA, Das YT. Insect Models for Biomedical Research. In: Woodhead AD, editor. Non mammalian Animal Models for Biomedical Research. Boca Raton, FL: CRC Press; 1989. p. 62-70.

35. Abramson CI, Wells H, Janko B. A social insect model for the study of ethanol induced behavior: the honey bee. In Yoshida, R. (Ed.), Trends in Alcohol Abuse and Alcoholism Research. Nova Sciences Publishers. 2007;197-218.

36. Cammaerts MC. Ants as models for examining potential adverse effects of products used by humans. JSM Anatomy and Physiology. 2018;3(1):1016.

37. Hölldobler B, Wilson EO. The ants. Berlin, Harvard University Press Springer-Verlag; 1990. pp. 732

38. Passera L, Aron S. Les fourmis: comportement, organisation sociale et évolution. Ottawa, Canada: Les Presses Scientifiques du CNRC; 2005. pp.480.

39. Billen J, Morgan ED. Pheromone communication in social insects sources and secretions. In: Vander Meer RK, Breed MD, Espelie KE, editors. Pheromone Communication in Social Insects: Ants, Wasps, Bees, and Termites; Boulder, Oxford: West view Press; 1998. 
40. Cammaerts MC, Cammaerts D. Comparative outlook over three Myrmica species' biotopes and foragers' know-how. Biologia. 2014;69(8):10511058.

41. Cammaerts MC, Cammaerts R. Ontogenesis of ants' cognitive abilities (Hymenoptera, Formicidae). Adv Stud Biol. 2015;7:335-348 .

42. Cammaerts MC, De Doncker P, Patris X, et al. GSM $900 \mathrm{MHz}$ radiations inhibits ants' association between food sites and encountered cues Electrom Biol Med. 2012;31(12):151-165.

43. Cammaerts MC, Rachidi Z, Bellens F, et al. Food collection and responses to pheromones in an ant species exposed to electromagnetic radiation. Electrom Biol Med. 2013;32(3):282-288.

44. Cammaerts MC, Cammaerts D. Environmental odors can affect individuals' physiology and ethology (a study on ants as models). Biology, Engineering and Medicine. 2018;3(5):10.

45. Cammaerts MC, Morel F, Martino F, et al. An easy and cheap softwarebased method to assess two-dimensional trajectories parameters. Belg $J$ Zool. 2012;142(2):145-151.
46. Cammaerts MC, Gosset G, Rachidi Z. Some physiological and ethological effects of nicotine; studies on the ant Myrmica sabuleti as a biological model. Int J Biol. 2014;6(4):64-81.

47. Siegel S, Castellan NJ. Non-parametric statistics for the behavioural sciences. Singapore: McGraw-Hill Book Company; 1989. pp. 396.

48. Cammaerts MC, Cammaerts R, Rachidi Z. Effects of four plants extract used as an anxiolytic; a study on ants as models. Adv Biomed Pharmacy. 2016;3(5):280-295.

49. McGaugh JL, Krivanek JA. Strychnine effects on discrimination learning in mice: effect of dose and time of administration. Physiology \& Behavior. 1970;5(12):1437-1442.

50. Chen J, Xiao HL, Hu R, et al. Pharmacokinetics of brucine after intravenous and oral administration to rats. Fitoterapia. 2011;82(8):1302-1308.

51. Bornhöft G, Matthiessen PF. Homeopathy in Healthcare. Effectiveness, Appropriateness, Safety, Costs. In: Bornhöft \& Matthiessen Editors. USA: Springer Verlag; 2011. 